\title{
Detection of some Heavy Metals Using Rhodamine B Isothiocyanate Fluoresceinated Dye
}

\author{
Azab H. A. ${ }^{1}$; Z. M. Anwar ${ }^{1}$; S. M. Saleh ${ }^{2}$; H. Elkady ${ }^{2}$ and E. M. Kilany ${ }^{2 *}$ \\ ${ }^{1}$ Department of Chemistry, Faculty of Science, Suez Canal University. \\ ${ }^{2}$ Chemistry Branch, Department of Science and Mathematics, Faculty of Petroleum and \\ Mining Engineering, Suez University.
}

\section{Received: $2 / 3 / 2016$}

\begin{abstract}
The spectral behavior of the binary complexes of Rhodamine B Isothiocyanate (RBITC) dye with metal ions in aqueous medium is studied. The observed fluorescence quenching of the dye reveals that the binding constant for RBITC dye-metal ions follow the order $\mathrm{Cu}^{2+}>\mathrm{Ni}^{2+}>\mathrm{Pb}^{2+}$. Also, the spectral changes of the interaction of the studied dye with metal ions in presence of ACES zwitterionic buffer (ternary complexes) is carried out, where the interaction of dye with ACES zwitterionic buffer is accompanied by as light increasing of the peak intensity at $\lambda=585 \mathrm{~nm}$ and the binding constant for dye-zwitterionic buffer- metal ion systems were determined where the order of binding with metal ions is as follows: $\mathrm{Pb}^{2+}>\mathrm{Ni}^{2+}>\mathrm{Cu}^{2+}$.
\end{abstract}

Keywords: Metals, Rhodamine B Isothiocyanate dye, Zwitterionic buffer, Binary complex, Ternary complexes.

\section{INTRODUCTION}

Rhodamine $\mathrm{B}$ is an amphoteric dye, although usually listed as basic as it has an overall positive charge. It is a highly water soluble, basic red dye of the xanthene class (Lide and Milne, 1994). It is found as a reddish violet powder. Rhodamine $\mathrm{B}$ can be used to dye silk, cotton, wool, fibers, nylon, acetate fibers, paper, spirit inks and lacquers, soap, wood stains, feathers, leather and distempers on china clay etc. It has also been used as a drug and cosmetic colour in aqueous drug solutions, tablets, capsules, toothpaste, soap, hair waving fluids, bath salts, lipsticks and rouges. It is often used as a tracer dye within water to determine the rate and direction of flow and transport. Therefore, the usage of RBITC as dye sensitizer is expected to reduce the negative impact of dye waste on environment (Jain et al., 2007).

Rhodamine B isothiocyanate (RBITC) was used as the fluorescent dye in this project. The structure of $\mathrm{Rh} B$ is very important in that the benzene ring structures provide the electrons capable of excitement and producing fluorescence. Changes to these structures leads to loss of this property known as photobleaching. This may not be a result of molecule breakdown into smaller molecules but just minor changes to the structure (Juan et al., 2008). The structure of Rhodamine B isothiocyanate (RBITC) dye is depicted in Figure (1).

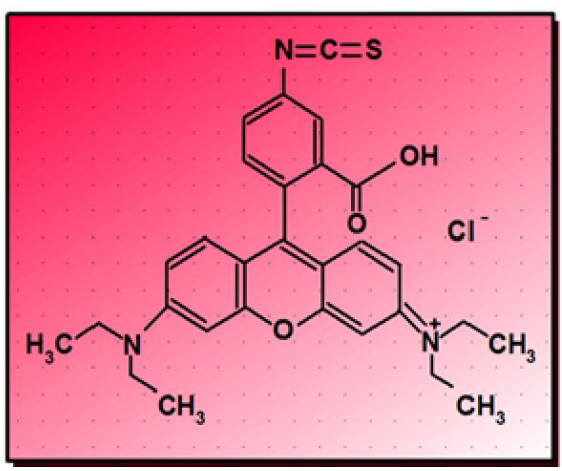

Fig. (1): Structure of Rhodamine B isothiocyanate (RBITC) dye.
Xanthene derivatives especially rhodamine dyes, occupy an important position among different families of dyes, owing to a number of reasons related to their photochemical and photophysical properties. Because of their high fluorescence quantum yield rhodamine dyes have wide spread technszological and scientific applications e.g., single molecule detection (Rigler et al., 1992; Keller et al., 1996), fluorescence labeling (Taylor et al., 1986), dye lasers (Drexhage, 1982; Peterson, 1979; Duarte and Hillmann, 1990), conversion and storage of solar energy (Archer and Ferreira, 1982) etc.

"Heavy metals" is a term which is used to define metals with elemental densities above $5 \mathrm{~g} / \mathrm{cm}^{3}$ (Morris, 1992). As many other metals they can be found in the earth's shell. Human body also contains small amount of these substances. Mainly they get to organisms via food, drinking water and air. Some heavy metals (e.g. copper, selenium, zinc) are involved in the metabolism of the human body (so called "essential elements") but at very low concentrations (WHO, 1996). If the concentrations of heavy metal in the environment and as a result in a body exceeds certain amount it can be toxic (Duffus, 2002). The reason of heavy metals poisoning is e.g. metals contained water pipes drinking water pollution, or air emissions from factories (Bradl, 2002; He et al., 2005).

Danger of heavy metals is in their ability for bioaccumulation. Bioaccumulation is a deposition of a chemical substance in a biological organism with an increase of its concentration in the organism every time this substance is emitted to the environment independently from its amount.

Accumulation of compounds in living things is faster than its decomposition and happens at any time they are exposed to the substance (Chang et al., 1996; Wang and Shi, 2001).

Environmental pollution from industry is main source of high amounts of heavy metals in the environment. Food poisoning is a consequence and the easiest way to enter human body (UNEP/GPA, 2004).

The aim of this work is to make different probes to detect heavy metal ions. 


\section{MATERIALS AND METHODS}

All materials employed in the present investigation were of A.R grade products from commercial sources (Sigma Aldrich) without further purifications. Rhodamine B Isothiocyanate (RBITC), ACES zwitterionic buffer N-(2-acetamido)-2aminoethanesulfonic acid and transition metal salts used are $\left(\mathrm{Cu}\left(\mathrm{NO}_{3}\right)_{2} \cdot 3 \mathrm{H}_{2} \mathrm{O}\right),\left(\mathrm{Ni} \quad\left(\mathrm{NO}_{3}\right)_{2} \cdot 6 \mathrm{H}_{2} \mathrm{O}\right)$ and $(\mathrm{Pb}$ $\left.\left(\mathrm{NO}_{3}\right)_{2} \cdot 3 \mathrm{H}_{2} \mathrm{O}\right)$.

The spectral behavior of the binary and ternary complexes were measured by A JASCO-FP6300 spectrofluorometer with $1 \mathrm{~cm}$ quartz cell was used for the emission and spectral measurements and $\mathrm{A}$ Shimadzu-UV Probe Version 2.33 UV-Visible automatic recoding spectrophotometer with $1 \mathrm{~cm}$ quartz cell). UV/VIS spectrometer was used to measure absorbance of light wavelengths in particular samples.

Procedures used for the absorbance spectra of RBITC dye in presence of zwitterionic buffers:

$1 \times 10^{-3}$ molL $^{-1}$ of zwitterionic buffers solution + $1 \times 10^{-3} \mathrm{molL}^{-1}$ of RBITC dye solution with Molar concentration ratio $(1: 1)$.

Procedures used for the measurements of the binding between RBITC dye and transition metals in aqueous medium (binary complexes):

$1 \times 10^{-3} \mathrm{molL}^{-1}$ of RBITC dye solution $+1 \times 10^{-3}$ molL $^{-1}$ of transition metals solution with Molar concentration ratio $(1: 1)$ to $1 \times 10^{-3} \mathrm{molL}^{-1}$ of RBITC dye solution $+1 \times 10^{-2}$ molL $^{-1}$ of transition metals solution with Molar concentration ratio (1:10).

Procedures used the measurements of the binding between RBITC dye, zwitterionic buffers and transition metals (ternary complexes) in aqueous medium:

(1) $1 \times 10^{-3} \mathrm{molL}^{-1}$ of zwitterionic buffers solution $+1 \times 10^{-3} \mathrm{molL}^{-1}$ of RBITC dye solution with Molar concentration ratio $(1: 1)$.

(2) $1 \times 10^{-3} \mathrm{molL}^{-1}$ of zwitterionic buffers solution $+1 \times 10^{-3} \mathrm{molL}^{-1}$ of RBITC dye solution + $1 \times 10^{-3} \mathrm{molL}^{-1}$ of transition metals with Molar concentration ratio $(1: 1: 1)$ to $1 \times 10^{-3} \mathrm{molL}^{-1}$ of zwitterionic buffers solution $+1 \times 10^{-3} \mathrm{molL}^{-1}$ of RBITC dye solution $+1 \times 10^{-2}$ molL $^{-1}$ of transition metals with Molar concentration ratio (1:1:10).

\section{RESULTS AND DISCUSSION}

Visible absorption and emission spectra for (RBITC) dye with various metal ion in aqueous medium:

The visible absorption spectra of $1 \times 10^{-3} \mathrm{molL}^{-1}$ of (RBITC) dye in aqueous medium was carried out. The dye exhibits a maximum absorption at $\lambda_{\max }=550 \mathrm{~nm}$, with a molar extinction coefficient equals to $0.54 \times 10^{3}$ $\mathrm{mol}^{-1} \mathrm{~L}$. The interaction of different metal ions with the dye was studied in pure aqueous medium by fluorescence measurements at $\lambda_{\mathrm{em}}=585 \mathrm{~nm}$ as shown in Figure (2 a, b).
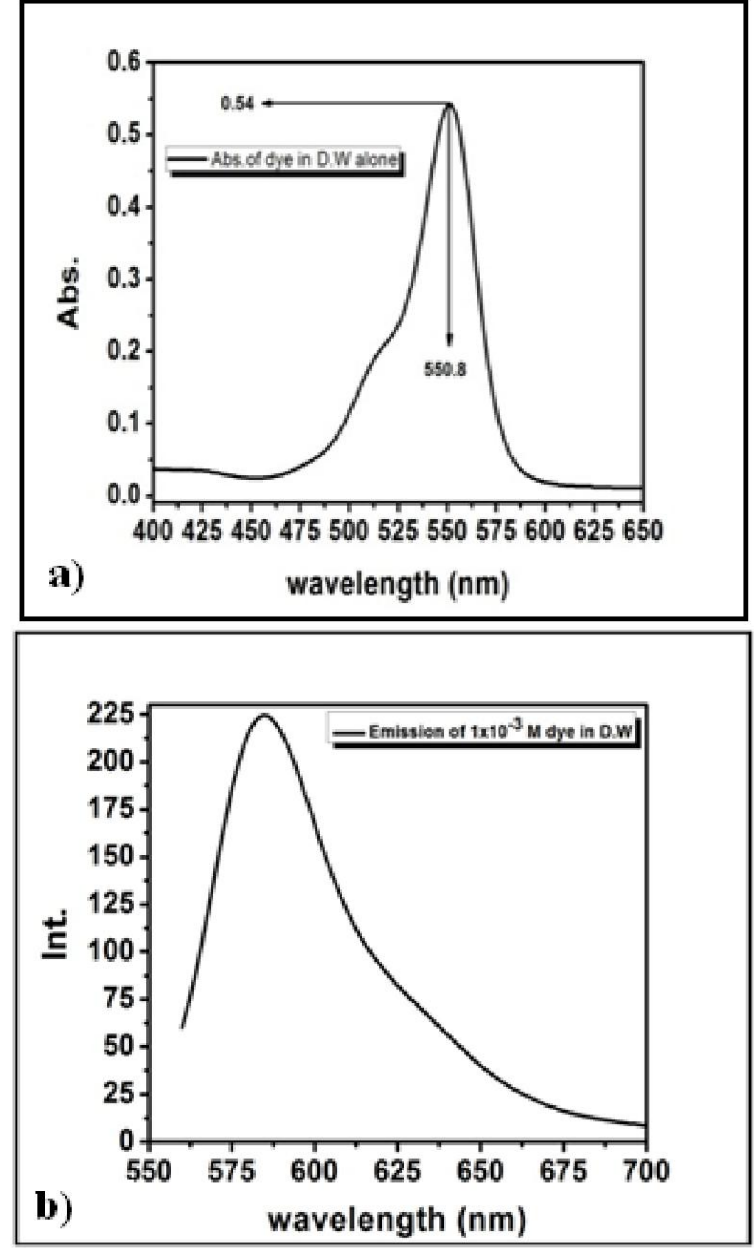

Fig. (2): Absorption and emission spectrum of $1 \times 10^{-3}$ molL ${ }^{-1}$ RBITC dye in aqueous medium.

The addition of metal ions in the concentration range of $1 \times 10^{-3}$ to $1 \times 10^{-2} \mathrm{molL}^{-1}$ with RBITC is accompanied by quenching Figures (3-5).

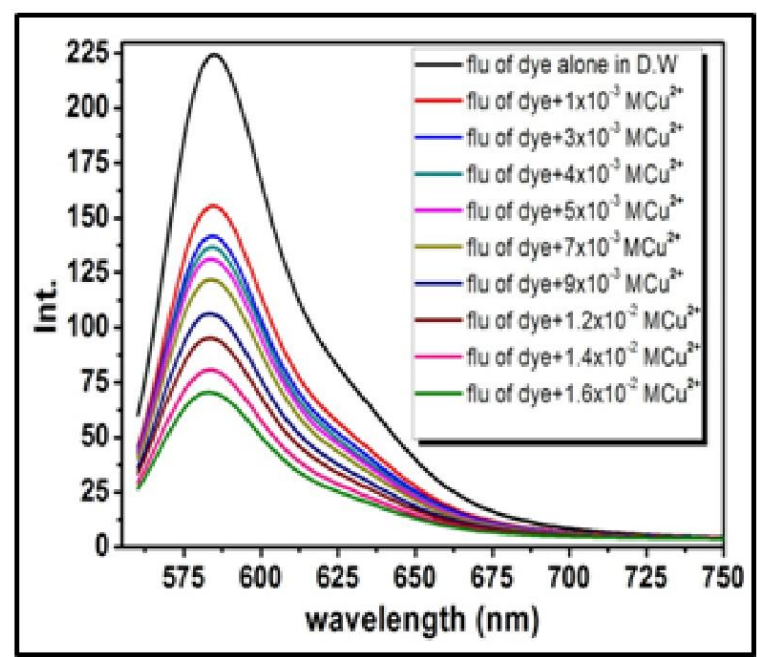

Fig. (3): Fluorescence spectra for the interaction of different concentrations of $\mathrm{Cu}^{2+}$ with $1 \times 10^{-3} \mathrm{molL}^{-1}$ of (RBITC) dye in aqueous medium $\left(\lambda_{\mathrm{ex}}=550 \mathrm{~nm}, \lambda_{\mathrm{em}}=\right.$ $585 \mathrm{~nm})$. 


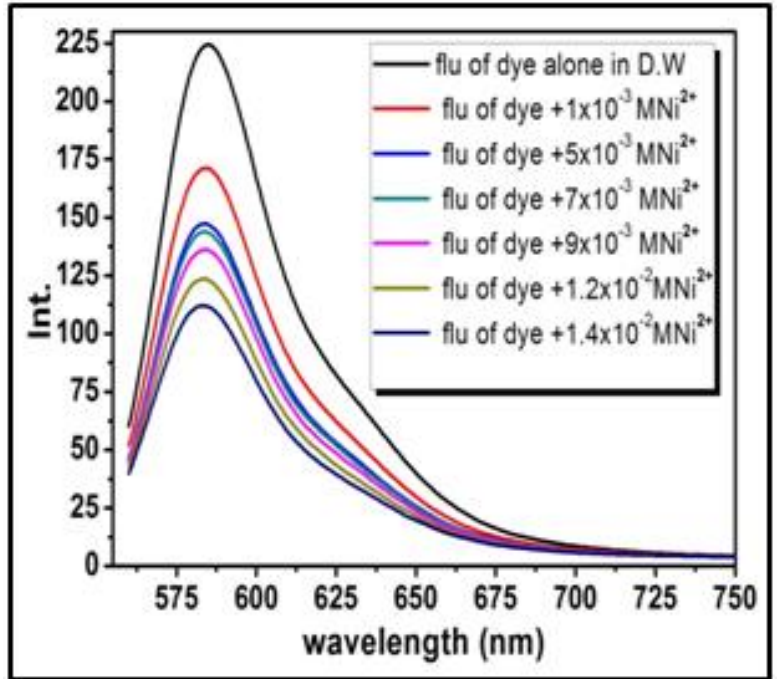

Fig. (4): Fluorescence spectra for the interaction of different concentrations of $\mathrm{Ni}^{2+}$ with $1 \times 10^{-3} \mathrm{molL}^{-1}$ of (RBITC) dye in aqueous medium $\left(\lambda_{\mathbf{e x}}=550 \mathrm{~nm}, \lambda_{\mathbf{e m}}=\right.$ $585 \mathrm{~nm})$.

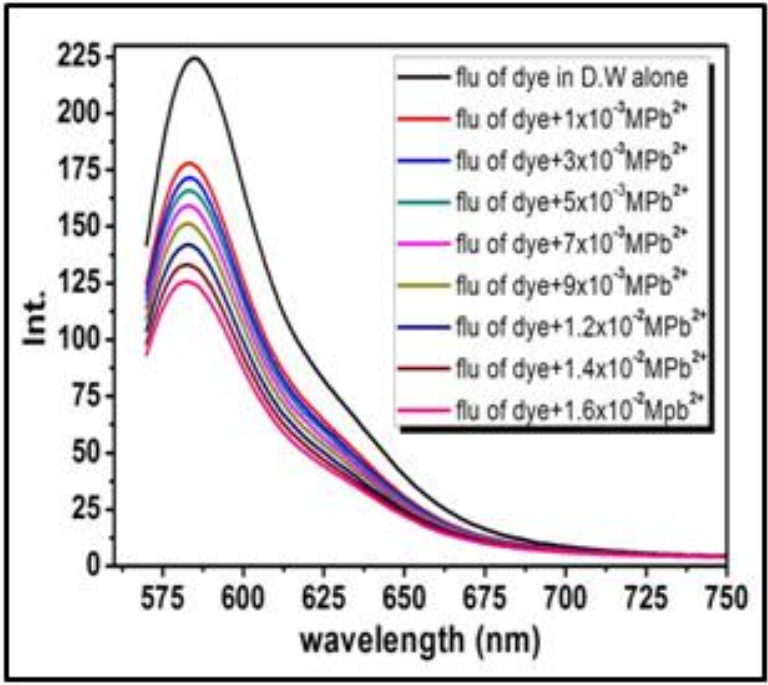

Fig. (5): Fluorescence spectra for the interaction of different concentrations of $\mathrm{Pb}^{2+}$ with $1 \times 10^{-3} \mathrm{molL}^{-1}$ of (RBITC) dye in aqueous medium $\left(\lambda_{\mathrm{ex}}=550 \mathrm{~nm}, \lambda_{\mathrm{em}}=\right.$ $585 \mathrm{~nm})$.

Applying Stern - Volmer equation (Lakowicz, 1999) $\longrightarrow \frac{\mathbf{F}^{\mathbf{0}}}{\mathbf{F}}=\mathbf{1}+\mathbf{K}_{\mathbf{S V}}$ [Q]

Where $\mathrm{F}^{0}, \mathrm{~F}$ are the fluorescence intensity of the free dye and the dye combined with metal ion, the Stern-Volmer constant $\mathrm{k}_{\mathbf{s v}}$ can be calculated for each metal ion. Table (1) and the data are represented in Figure (6).

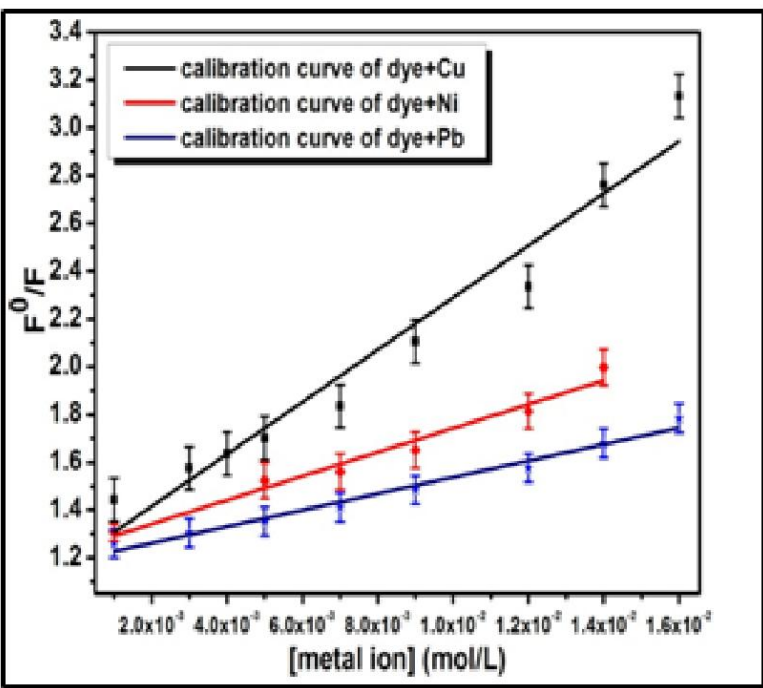

Fig. (6): Calibration plot for metal ions from the fluorescence spectra of its interaction with (RBITC) dye in aqueous medium.

Table (1): Stern-Volmer quenching constant (Ksv), Limit of detection (LOD), Limit of quantitation (LOQ) for the interaction of metal ions with (RBITC) dye in aqueous medium.

\begin{tabular}{|c|c|c|c|c|c|}
\hline Metal ions & $\mathrm{K}_{\mathrm{sv}}\left(\mathrm{mol}^{-1} \mathrm{~L}\right)$ & $\mathbf{R}$ & $\operatorname{SD}(\sigma)$ & LOD $\left(\mathrm{mmolL}^{-1}\right)$ & $\mathrm{LOQ}\left(\mathrm{mmolL}^{-1}\right)$ \\
\hline $\mathrm{Cu}^{2+}$ & 109.0984 & 0.95282 & 0.1112 & 3.056416 & 10.188054 \\
\hline $\mathrm{Ni}^{2+}$ & 50.10541 & 0.96649 & 0.0078 & 0.464022 & 1.546739 \\
\hline $\mathbf{P b}^{2+}$ & 34.42991 & 0.97766 & 0.0046 & 0.403428 & 1.344761 \\
\hline
\end{tabular}


The binding constant of the studied metal the application of Lineweaver- Burk equation on the obtained data Figure (7). The data are collected in Table (2). Lineweaver-Burk equation (Beckford, 2009) is applied in the form:-

$$
\frac{1}{F^{0}-F}=\frac{1}{F^{0} k_{a}[Q]}+\frac{1}{F^{0}}
$$

Where ka is the binding constant of RBITC with the quencher (metal ions) in molL-1. The data reveal that, the binding constants of the metal ions with RBITC dye following the order $\{\mathrm{Cu} 2+>\mathrm{Ni} 2+>\mathrm{Pb} 2+\}$.

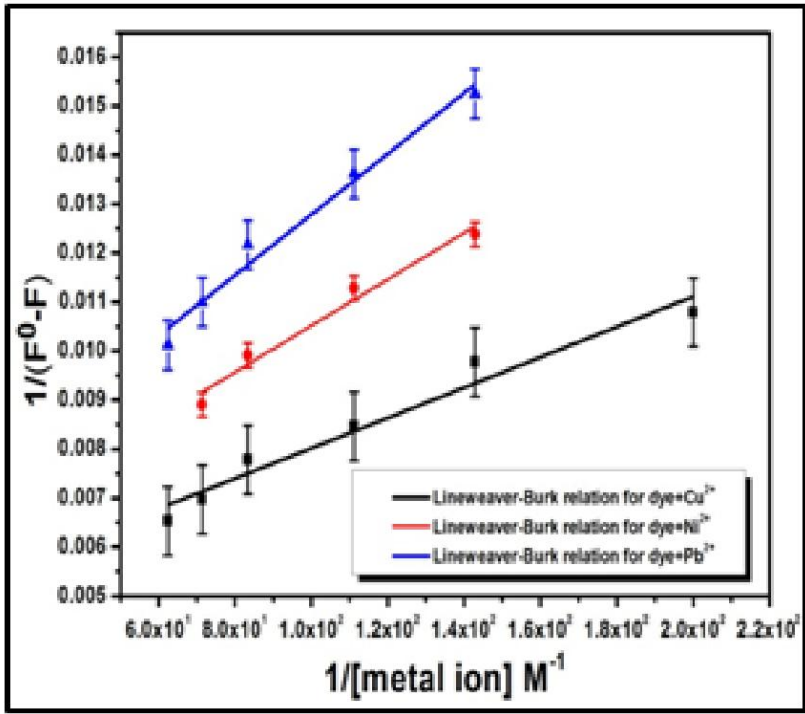

Fig. (7): Line weaver-Burk equation plot for the interaction of different concentrations of metal ions with (RBITC) dye in aqueous medium.

Table (2): Binding constant $\left(\mathrm{K}_{\mathrm{a}}\right)$ of metal ions with (RBITC) dye in aqueous medium.

\begin{tabular}{lccc}
$\begin{array}{l}\text { Metal } \\
\text { ions }\end{array}$ & $\mathbf{K}_{\mathbf{a}}\left(\mathbf{m o l}^{-1} \mathbf{L}\right)$ & $\mathbf{R}$ & $\mathbf{S D}(\boldsymbol{\sigma})$ \\
\hline $\mathbf{C u}^{2+}$ & 284.8935 & 0.95821 & $2.56 \times 10^{-6}$ \\
$\mathbf{N i}^{2+}$ & 122.4529 & 0.98674 & $1.84 \times 10^{-7}$ \\
$\mathbf{P b}^{2+}$ & 106.4065 & 0.98973 & $3.44 \times 10^{-7}$ \\
\hline
\end{tabular}

R: Correlation coefficient; SD (б): Standard deviations

Visible absorption and emission spectra for (RBITC) dye with various metal ions in the presence of ACES zwitterionic buffer:

The zwitterionic amino acid buffer solutions recommended by Good et al. (1966) and Ferguson et al.
(1980) have been studied in the authors' laboratory for the purpose of $\mathrm{pH}$ measurement control in the physiological range of $\mathrm{pH}$. Concerning the current investigation, the authors' goal is to provide $\mathrm{pH}$ values for the ACES, which is depicted by the following structure:-

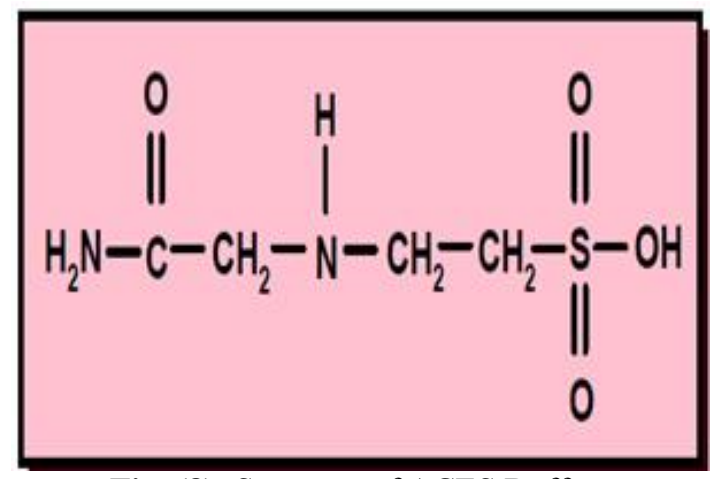

Fig. (8): Structure of ACES Buffer.

The zwitterionic buffer compound ACES may form complexes with cations such as $\mathrm{Mg}^{+2}$ and $\mathrm{Ca}^{+2}$. At a high $\mathrm{NaCl}$ concentration, the complex formation is mini-mized.

ACES is a zwitterionic buffer used in biochemistry and molecular biology research. It is one of the Good buffers developed in the 1960's to provide buffers in the $\mathrm{pH}$ range of $6.15-8.35$ for wide applicability to biochemical studies.

The potential inhibition of ACES and other Good buffers in $\gamma$-aminobutyric acid receptor binding to rat brain synaptic membranes has been investigated (Tunnicliff and Smith, 1981). The survival of a strain of Listeria monocytogenes Scott A tolerant to high hydrostatic pressure has been studied in ACES buffer (Karatzas and Bennik, 2002).

ACES was used recently to assist calorimetric determination of the affinity of $\mathrm{Cu}$ (II) to Alzheimer's Disease's A $\beta$ peptide and some other bioligands (Grossoehme et al., 2010; Sacco et al., 2012).

The absorption and emission spectra for $1 \times 10^{-3}$ molL $^{-1}$ of (RBITC) dye, and the interaction with $1 \times 10^{-3}$ molL ${ }^{-1}$ of ACES buffer, where a considerable decrease in the absorbance value is observed with as light shift in the maximum absorptivity, also, a slight increase of the peak intensity at $\lambda=585 \mathrm{~nm}$ is obtained when the dye is interacted with the zwitterionic buffer molecule, which could be assigned to the formation of associates between the two molecules Figure ( $9 a, b)$.

The interaction of $1 \times 10^{-3} \mathrm{molL}^{-1}$ of the studied metal ions $\left(\mathrm{Cu}^{2+}, \mathrm{Ni}^{2+}, \mathrm{Pb}^{2+}\right)$ with $1 \times 10^{-3} \mathrm{molL}^{-1}$ of (RBITC) dye in the presence of $1 \times 10^{-3} \mathrm{molL}^{-1}$ of ACES buffer is studied by monitoring the change in fluorescence at $\lambda=585 \mathrm{~nm}$, where quenching effect is observed in the case of all the concerned metal ions Figures (10, 11 and 12). 

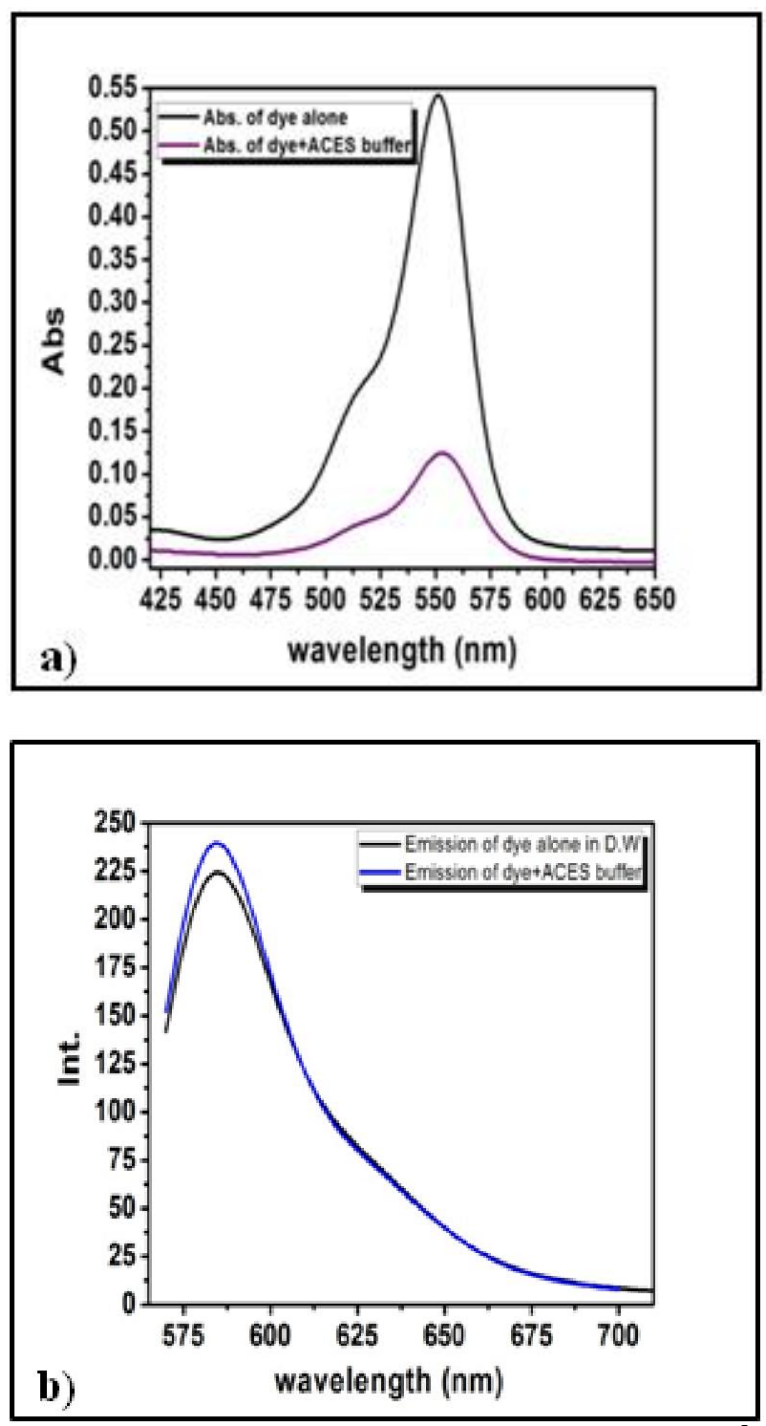

Fig. (9): Absorption and emission spectra of $1 \times 10^{-3}$ molL ${ }^{-1}$ RBITC dye and $1 \times 10^{-3} \mathrm{molL}^{-1}$ of ACES buffer.

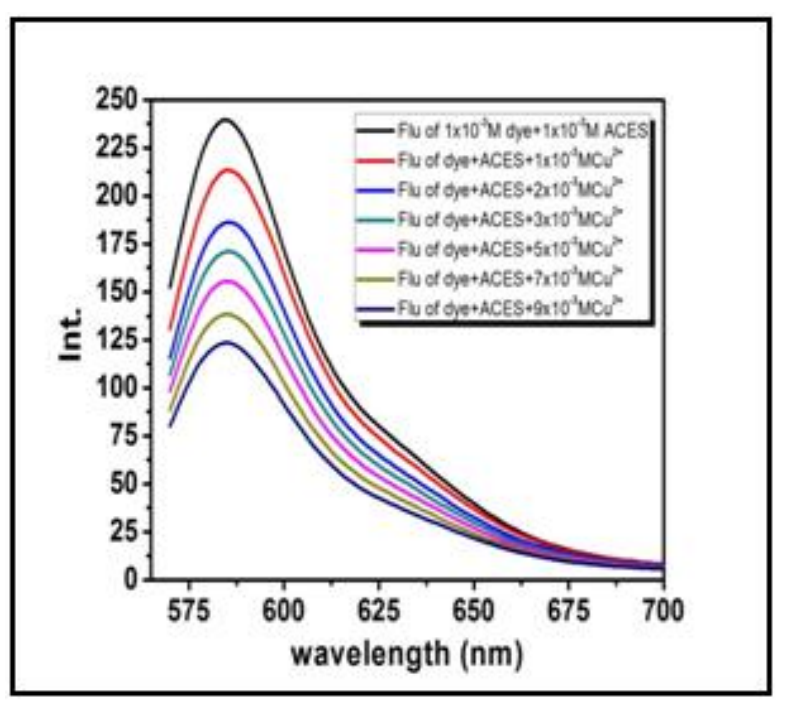

Fig. (10): Fluorescence spectra for the interaction of different concentrations of $\mathrm{Cu}^{2+}$ with $1 \times 10^{-3} \mathrm{molL}^{-1}$ of (RBITC) dye (in the presence of $1 \times 10^{-3} \mathrm{molL}^{-}$ ${ }^{1}$ zwitterionic buffer ACES) in aqueous medium.

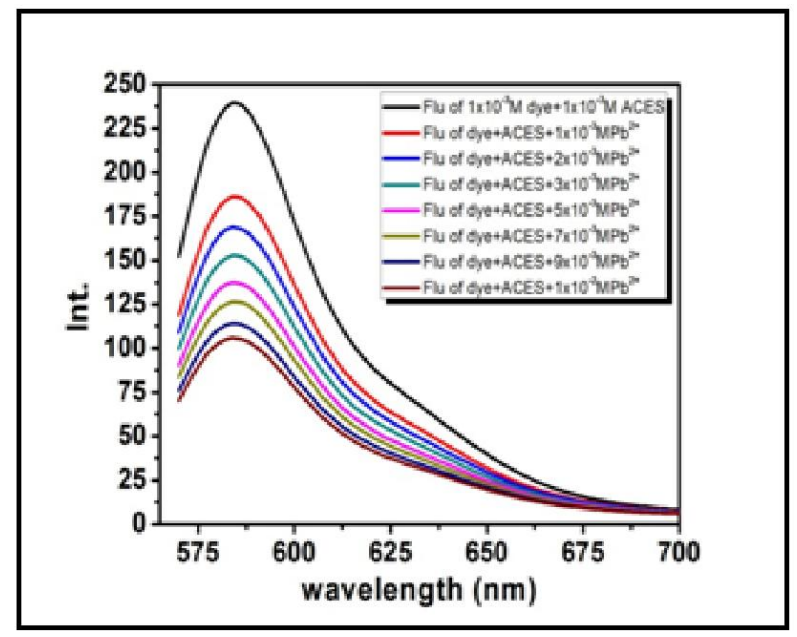

Fig. (11): Fluorescence spectra for the interaction of different concentrations of $\mathrm{Pb}^{2+}$ with $1 \times 10^{-3} \mathrm{molL}^{-1}$ of

(RBITC) dye (in the presence of $1 \times 10^{-3} \mathrm{molL}^{-}$

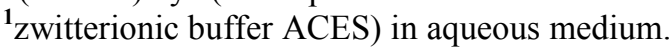

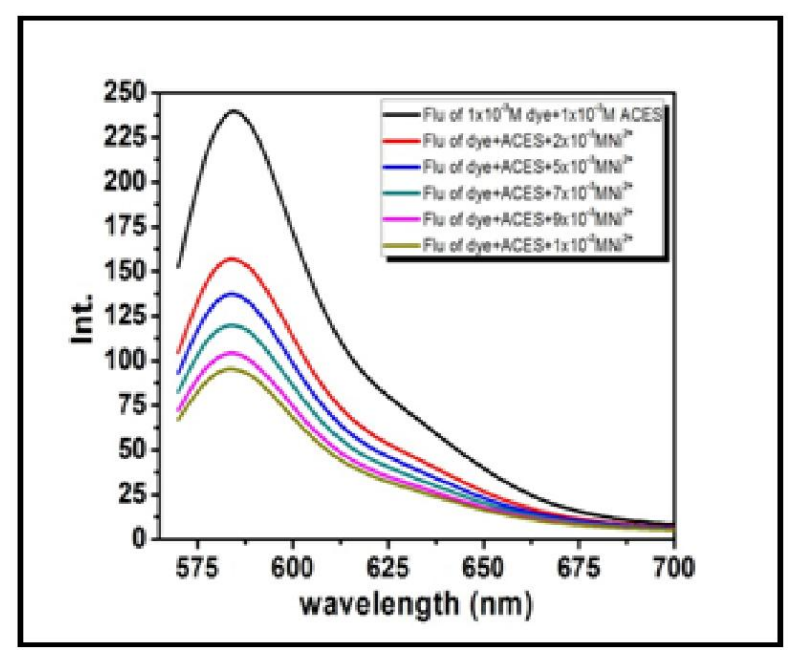

Fig. (12): Fluorescence spectra for the interaction of different concentrations of $\mathrm{Ni}^{2+}$ with $1 \times 10^{-3} \mathrm{molL}^{-1}$ of (RBITC) dye (in the presence of $1 \times 10^{-3} \mathrm{molL}^{-1}$ zwitterionic buffer ACES) in aqueous medium.

The Stern-Volmer quenching constants were calculated and collected in Figure (13), Table (3).

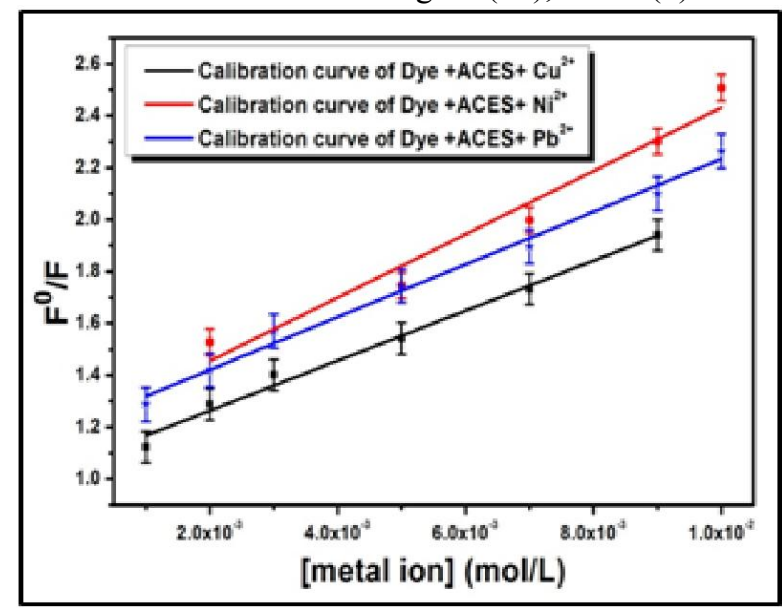

Fig. (13): Calibration plot for metal ions from the fluorescence spectra of its interaction with (RBITC) dye in aqueous medium containing ACES zwitterionic buffer. 
Table (3): Stern-Volmer quenching constant $\left(\mathrm{K}_{\mathrm{sv}}\right)$, Limit of detection (LOD), Limit of quantitation (LOQ) for the interaction of metal ions with (RBITC) dye in aqueous medium containing ACES zwitterionic buffer.

\begin{tabular}{|c|c|c|c|c|c|}
\hline Metal ions & $K_{\mathrm{sv}}\left(\mathrm{mol}^{-1} \mathrm{~L}\right)$ & $\mathbf{R}$ & $\operatorname{SD}(\sigma)$ & LOD $\left(\mathrm{mmol} \mathrm{L}^{-1}\right)$ & LOQ $\left(\mathrm{mmol} \mathrm{L}^{-1}\right)$ \\
\hline $\mathrm{Cu}^{2+}$ & 96.38899 & 0.98726 & 0.9277 & 2.887363 & 9.624543 \\
\hline $\mathrm{Ni}^{2+}$ & 122.064 & 0.95499 & 0.02145 & 0.527182 & 1.757275 \\
\hline $\mathbf{P b}^{2+}$ & 101.528 & 0.98971 & 0.00654 & 0.193247 & 0.644157 \\
\hline
\end{tabular}

R: Correlation coefficient; SD (б): Standard deviations.

The binding constant values for the metal ions with the two ligands (dye and ACES) were calculated by using Lineweaver-Burk equation Figures (14), and the data are collected in Table (4), the binding follows the order: $\left\{\mathrm{Pb}^{2+}>\mathrm{Ni}^{2+}>\mathrm{Cu}^{2+}\right\}$.

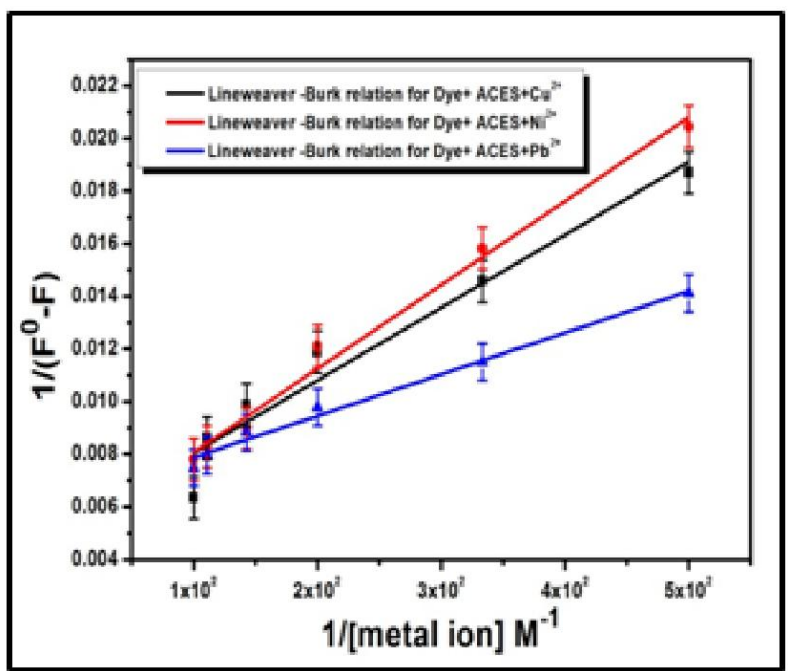

Fig. (14): Lineweaver-Burk equation plot for the interaction of different concentrations of metal ions with (RBITC) dye in aqueous medium containing ACES zwitterionic buffer.
Table (4): Binding constant $\left(\mathrm{K}_{\mathrm{a}}\right)$ of metal ions with (RBITC) dye in aqueous medium containing zwitterionic buffer (ACES).

\begin{tabular}{lccc}
$\begin{array}{l}\text { Metal } \\
\text { ions }\end{array}$ & $\mathbf{K}_{\mathbf{a}}\left(\mathbf{m o l}^{-1} \mathbf{L}\right)$ & $\mathbf{R}$ & $\mathbf{S D}(\boldsymbol{\sigma})$ \\
\hline $\mathbf{C u}^{2+}$ & 125.1478 & 0.98406 & $\begin{array}{c}9.3214 \mathrm{X} \\
10^{-6}\end{array}$ \\
& & & \\
$\mathbf{N i}^{2+}$ & 152.5468 & 0.99083 & $\begin{array}{c}2.8797 \mathrm{X} \\
10^{-8}\end{array}$ \\
& & & \\
$\mathbf{P b}^{2+}$ & 573.2905 & 0.97153 & $2.2944 \mathrm{X}$ \\
& & & $10^{-6}$ \\
\hline
\end{tabular}

R: Correlation coefficient; SD ( $\boldsymbol{\sigma})$ : Standard deviations.

In comparison to the binding constant of metal ions with the RBITC dye in a pure aqueous medium, $\mathrm{Cu}^{2+}$ exhibit low binding constant in the presence of zwitterionic buffer ACES, which may be attributed to the strong binding of $\mathrm{Cu}^{2+}$ with ACES (Taha et al., 2007; Azab et al., 2000; Pope et al., 1980; Sigel and Martin, 1982) as shown in Figure (15).

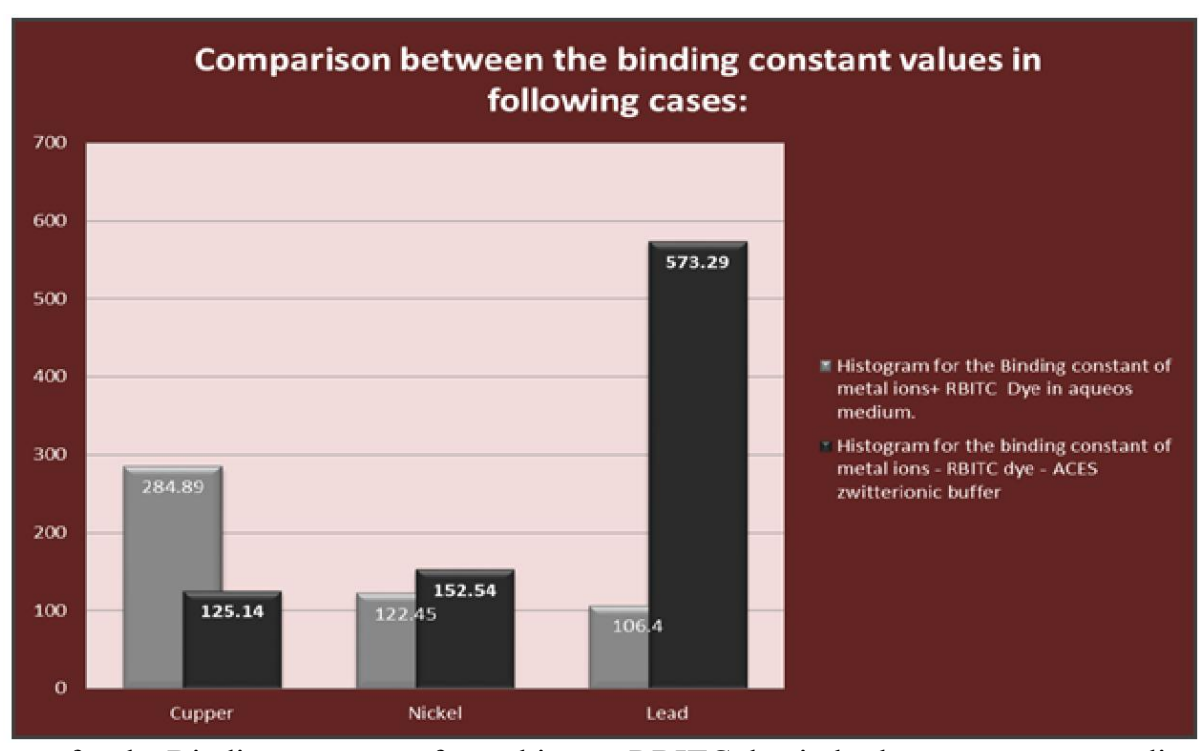

Fig. (15): Histogram for the Binding constant of metal ions - RBITC dye in both pure aqueous medium and in presence of ACES zwitterionic buffer. 
Hence the net result gives lower value of binding with the dye. In contrary, the other metal ions acquire high binding constants values in ACES buffer than with the dye only. The promising result is the great increase in the binding constant of $\mathrm{Pb}^{2+}$ with the dye in presence of ACES zwitterionc buffer.

\section{REFERENCES}

Archer, M. D. and M. I. C. Ferreira (1982). Photochemical Conversion and Storage of Solar Energy. In: J. S. Connolly (ed.), Academic Press, New York, 201.

Azab, H. A., F. S. Deghaidy, A. S. Orabi and N. Y. Farid (2000). Comparison of the effectiveness of various metal ions on the formation of the ternary complexes containing adenosine 5'mono-, 5'-di-, and 5'-triphosphate and some zwitterionic buffers for biochemical and physiological research. J. Chem. Eng. Data, 45: 709-715.

Beckford, F. A. (2009). Int. J. Inorg. Chem, 2010: 975756. Synthesis, characterisation, and preliminary in vitro studies of vanadium (IV) complexes with a Schiff base and thiosemicarbazones as mixed ligands.

Bradl, H. (2002). Heavy Metals in the Environment: Origin, Interaction and Remediation. London: Academic Press; 6.

Chang, L. W., L. Magos and T. Suzuki (1996). Toxicology of Metals. Boca Raton. FL, USA: CRC Press.

Drexhage, K. H. (1982). Dye Lasers (F. P. Schäfer, ed.), Springer-Verlag, Berlin, Heidelberg.

Duarte, F. J. and L. W. Hillmann (1990). Dye Laser Principles. Academic Press Inc., New York.

Duffus, J. H. (2002). Heavy metals-a meaningless term? Pure Appl. Chem., 74(5): 793-807.

Ferguson, W. J., K. L. Braunschweiger, W. R. Braunschweiger, J. R. Smith, J. J. McCormick, C. C. Wasmann, N. P. Jarvis, D. H. Bell and N. E. Good (1980). Hydrogen Ion Buffers for Biological Research. Analytical Biochemis-try, 104: 300-310.

Good, N. E., G. D. Winget, W. Winter, T. N. Connolly, S. Izawa and R. M. M. Singh (1966). Hydrogen Ion Buffers for Biological Research. Biochemistry, 5(2): 467-477.

Grossoehme, N. E., A. M. Spuches and D. E. Wilcox (2010). $\mathrm{Cu}$ (II) complex formation by ACES buffer. J. Biol. Inorg. Chem., 15: 1183-1191.

He, Z. L., X. E. Yang and P. J. Stoffella (2005). Trace elements in agroecosystems and impacts on the environment. J. Trace Elem Med Biol., 19 (23): $125-140$.

Jain, R., M. Mathr, S. Sikarwar and A. Mittal (2007). Removal of the Hazardous Dye Rhodamine B Through Photocatalytic and Adsorption Treatments. Journal of Environmental Management, 85: 956-964.

Juan, L., M. Fang, L. Wen-You, H. Xi-Wen and Y. K. Zhang (2008). Study on the fluorescence resonance energy transfer between CdTe QDs and butyl-rhodamine $\mathrm{B}$ in the presence of CTMAB and its application on the detection of $\mathrm{Hg}$ (II). Spectrochimica Acta Part A, 70: 811817.

Karatzas, K. A. and M. H. Bennik (2002). Characterization of a Listeria monocytogenes Scott A isolate with high tolerance towards high hydrostatic pressure. Appl. Environ. Microbiol., 68(7): 3183-3189.

Keller, R. A., W. P. Ambrose, P. M. Goodwin, J. H. Jett, J. C. Martin and M. Wu (1996). Singlemolecule fluorescence analysis in solution. Appl. Spectroscopy, 7: 12A-32A.

Lakowicz, J. R. (1999). Principles of "Fluorescence Spectroscopy" $2^{\text {nd }}$, Kluwer Academic /Plenum Plublishers.

Lide, D. R. and G. W. A. Milne (1994). Handbook of Data on Organic Compounds: Compounds, Boca Raton: CRC Press, 1001-15600.

Morris, C. (Ed.) (1992). Academic Press Dictionary of Science and Technology, Academic Press, San Diego.

Peterson, O. G. (1979). Methods of Experimental Physics (C. L Tang, ed.), Academic Press Inc., New York.

Pope, J. M., P. R. Stevens, M. T. Angotti and R. Nakon (1980). Free metal ion depletion by "good's" buffers: II. N-(2-acetamido)-2aminoethanesulfonic acid (ACESH): Complexes with Calcium (II), Magnesium (II), Manganese (II), Cobalt (II), Zinc (II), Nickel (II), and Cooper (II). Anal. Biochem. 103: 214-221.

Rigler, R., J. Widengren and Ü. Mets (1992). Fluorescence spectroscopy (Wolfbeis, ed.), Springer-Verlag, 13.

Sacco, C., R. A. Skowronsky, S. Gade, J. M. Kenney and A. M. Spuches (2012). Calorimetric investigation of copper (II) binding to $A \beta$ peptides: thermodynamics of coordination plasticity. J. Biol. Inorg. Chem. 17: 531-541.

Sigel, H. and R.B. Martin (1982). Coordinating properties of the amide bond. Stability and structure of metal ion complexes of peptides and related ligands, Chem. Rev. 82: 385-426.

Taha, M., R. A. Saqr and A. T. Ahmed (2007). Thermodynamic studies on complexation of divalent transition metal ions with some zwitterionic buffers for biochemical and physiological research. J. Chem. Thermodyn. 39: 304-308.

Taylor, D. L., A. S. Waggoner, R. F. Murphy, F. Lanni and R. R. Birge (1986). Applications of Fluorescence in the Biomedical Sciences. Alan R. Liss Inc., New York.

Tunnicliff, G. and J. A. Smith (1981). Competitive inhibition of $\gamma$-aminobutyric acid receptor binding by N-2-hydroxyethylpiperazine-N'-2- $\varepsilon$ ethanesulfonic acid and related buffers. J. Neurochem., 36(3): 1122-1126.

United Nations Environmental Protection/Global Program of Action UNEP/GPA Coordination Office (2004). Why The Marine Environment 
Needs Protection From Heavy Metals, Heavy Metals.

Wang, S. and X. Shi (2001). Molecular mechanisms of metal toxicity and carcinogenesis. Mol Cell Biochem., 222: 3-9.
World Health Organization (1996). Switzerland: Geneva; WHO/FAO/IAEA, Trace Elements in Human Nutrition and Health.

\section{الكثف عن بعض أيونات المعادن الثقيلة باستخدام الصبغة القلورسينية (الرودأمين أيزوثيوسبانات)

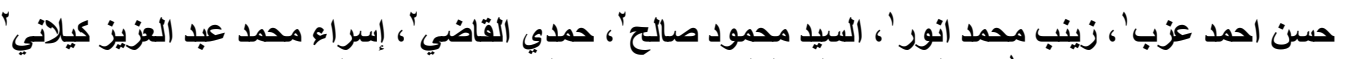

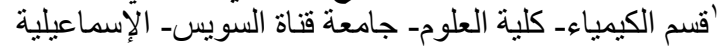 'فرع الكيمياء- قسم العلوم و الرياضيات الهنديةـ كلية هندسة البترول و التعدين- جامعة السويس العيس}

لقد تم دراسة السلوك الطيفي لصبغة الرودامين أيزوثيوسيانات في وجود بعض من أيونات المعادن الثقيلة (تكوين متر اكب ثنائي) في التي

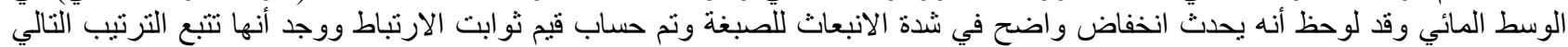

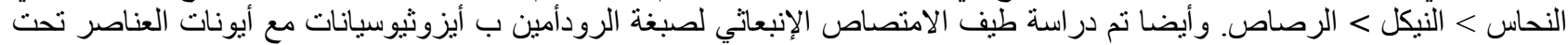

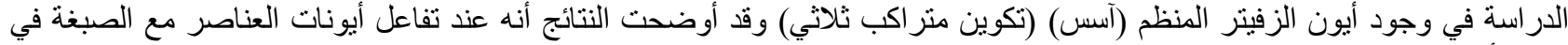

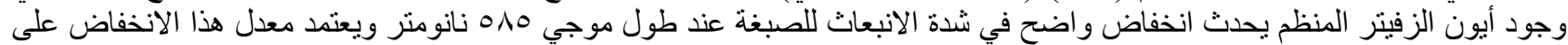

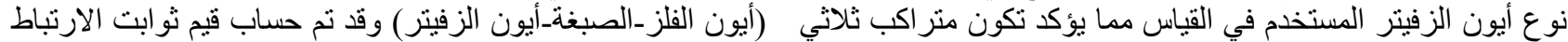

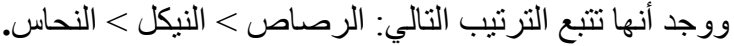

